\title{
Intussusception Presenting as Rectal Prolapse
}

Asrar Ahmad, Irum Saleem, Mahwish Mahboob Bhutta. Mehwish Mooghal, Nisar Ahmad

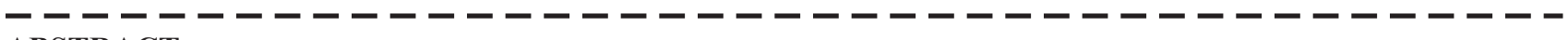
ABSTRACT:

Intussusception is the invagination of a segment of the intestine into the lumen of the distal or proximal segment. It is one of the commonest causes of intestinal obstruction in the toddlers. Ileo-colic intussusception is the most common type. At times the inussusceptum may protrude through the anal canal and mimic a rectal prolapse. The diagnosis may be delayed in such cases leading to increase morbidity as well as mortality. Therefore, a high index of suspicion is required in such cases. In this case where a colo-colic intussusception presented like rectal prolapse. Emergency surgical reduction was carried out under general anaesthesia and the baby had a smooth recovery.
\end{abstract}

Keywords: Anal canal, Intussusception, Intestine, Prolapse.

How to cite this Article:
Ahmad Asrar, Saleem I, Bhutta MM, Mooghal M, Ahmad N. Intussusception Presenting as Rectal Prolapse. J Bahria Uni Med Dental
Coll. $2021 ; 11(3): 136-137$. DOI: https://doi.org/10.51985/KRUB8912
This is an Open Access article distributed under the terms of the Creative Commons Attriution Non Commercial Liciense (http:// creativecommons/org/licences/by-nc/4.0)
which permits unrestricted non commercial use, distribution and reproduction in any medium, provided the original work is properly cited. - - - - - - - - - - - - - - - - - - - -

\section{INTRODUCTION:}

Intussusception is defined as the invagination of a segment of the intestine into the lumen of the distal or proximal segment. The invaginating loop is known as intussusceptum and the receiving part is called intussuscepiens. Intussusception is the most common cause of acute intestinal obstruction in children under 2 years of age. ${ }^{1}$ Children present usually with the classical signs of small bowel obstruction (SBO). Bilious vomiting, abdominal distension, and severe colicky pain abdomen is accompanied by red currant jelly stools and palpable mass in the lower abdomen. At times the invaginating loop may protrude through the anal canal and present as a prolapsed rectum. In one case series its prevalence has been claimed to be $29 \%$ of all the cases. $^{2}$ A high index of suspicion is required in such cases as prompt management is required in order to avoid ischaemic injury to the involved loop of intestine. Here we present a similar case of a baby girl who presented with a mass protruding through the anus.

Asrar Ahmad
I Assistant Professor Department of Surgery
INS Shifa Hospital, Karachi.
E-mail:drasrar.ahmad@yahoo.com
Irum Saleem
Resident, Department of Obs and Gynae
I Bahria University, Medical dental College, Karachi
I Mahwish Mahboob Bhutta
I Besident, Department of Surgery
I Mehwish Mooghal
I Besident, Department of Surgery
I Bahria University, Medical dental College, Karachi
I Nisar Ahmad
I Hayat Abad Medical Complex, Peshawar
I Received: 24-05-2021
I Accepted: 29-06-2021
| I - I

\section{CASE REPORT:}

A three years old baby girl presented to the emergency department in the evening with history of severe colicky pain in the abdomen and anorexia since morning. She developed a mass protruding through the anus in afternoon which gradually increased in length. She was also passing mucus and blood in stools. On examination she was irritable and crying with pain. An almost $15 \mathrm{~cm}$ long mass was coming out of anus (Figure.1). Her pulse rate was 120/min. She looked pale and was afebrile. She had guarding and tenderness in her lower abdomen however, no mass was palpable. A finger could be easily passed between the two loops of the protruding gut and anal canal. Her blood complete counts and electrolytes were normal. Ultrasound of the abdomen was suggestive of "target sign" with central echogenic and peripheral hypoechoic portion of gut in the pelvis. Longitudinal scan showed "pseudo-kidney sign". On colour doppler blood flow was present in both loops, suggesting colo-colic intussusception. She was admitted and prepared for emergency laparotomy. Under general

Figure.1 Intussusception protruding through anus mimicking rectal prolapse

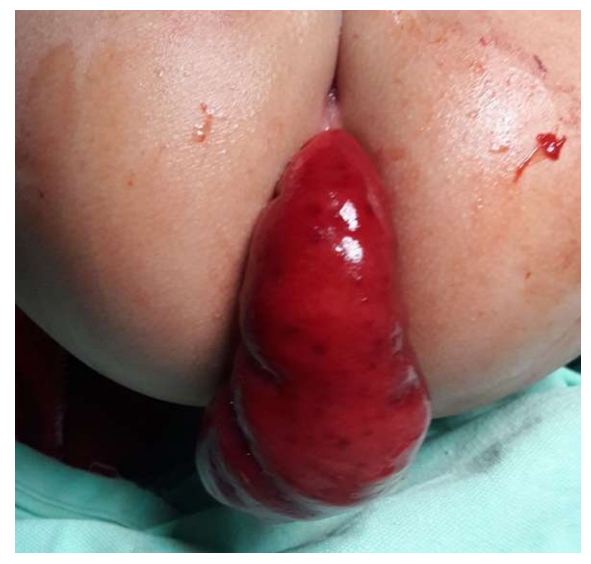


Figure.2: Last part of intussusception being reduced easily

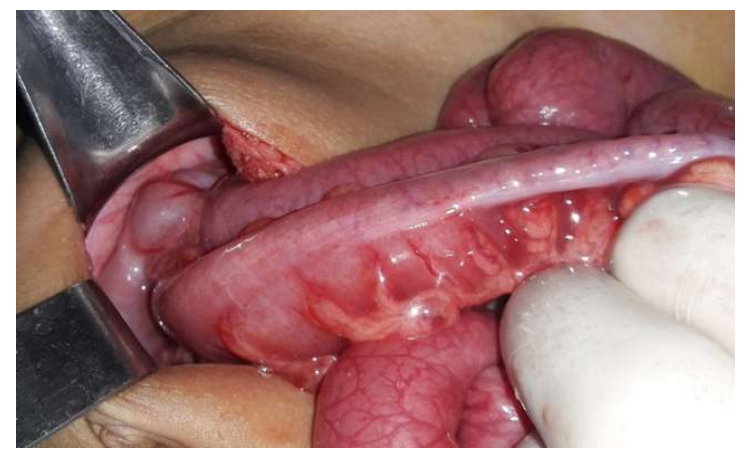

anaesthesia the intussusception was kept in hot saline packs for 10 minutes and then reduction was tried through anus but could not be reduced. A lower transverse incision was made and the intussusception was reduced easily (Figure.2). She made an uneventful recovery and was discharged on second post-operative day.

\section{DISCUSSION:}

Intussusception is a well-known cause of intestinal obstruction in children. The exact aetiology is still unknown and almost $81 \%$ of the cases are idiopathic. ${ }^{3}$ Various conditions have been found to be associated with it. ${ }^{4}$ Adenovirus infection ${ }^{5}$ as well as vaccination against rota virus have been proposed to increase the risk of intussusception. ${ }^{6}$ It can occur at any age, but $80-90 \%$ of the cases are usually less than two years old. ${ }^{7}$ Ileo-colic is the most common type but it is uncommon to prolapse through the anus. The colo-colic or sigmorectal is the relatively uncommon but likely to protrude through the anus as it was found in our case. Pathological lead point (PLP) may be present in $20 \%$ cases and mostly presenting in children more than one year of age. The age of patient in our case was 3 years however, there was no PLP. Patients present with signs of SBO. Vomiting is almost found in more than $80 \%$ cases. Our patient had nausea but no vomiting because the obstruction was distal and moreover, she presented early to the emergency department. Ultrasound of the abdomen is the investigation of choice with more sensitivity and high specificity. ${ }^{8}$ Once there is prolapse of intussusception it can be easily diagnosed by insinuating finger between the anal canal and the intussusception to differentiate it from the rectal prolapse. In rectal prolapse a finger cannot be passed freely beyond anus between the prolapsing mucosa and the anal canal but it will easily go around the intussusception. Spontaneous resolution of the intussusception may occur in a few cases but most would require hydrostatic reduction or surgery. Recurrence is more in cases of hydrostatic reduction. Similarly, children older than one year, having vomiting and palpable mass were found to be at high risk of recurrence. ${ }^{9}$
A high index of suspicion is needed to diagnose children having protrusion of the intussusception through anus. These are the cases confused with rectal prolapse. Moreover, they do not present with the classical signs of the disease. Delayed treatment may lead to gangrene of the involved segment of the gut thus increasing the morbidity and mortality by many folds. ${ }^{10}$

\section{CONCLUSION:}

Both intussusception and rectal prolapse are common in toddlers. Rectal prolapse is usually managed conservatively. On the other hand intussusception if left untreated can lead to gangrene of the involved segment of intestine and has high mortality and morbidity. A high index of suspicion is needed to differentiate the two conditions and initiate prompt management.

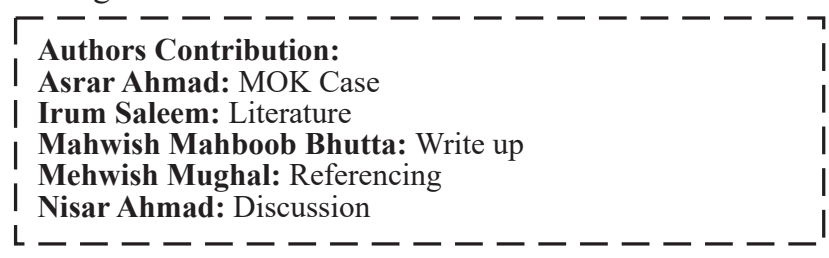

\section{REFERENCES:}

1. Rotavirus vaccines. WHO position paper- January2013. Wkly Epidemiol Rec.2013;88(5):49-64.

2. Ameh EA, Mshelbwala PM: Transanal protrusion of intussusception in infants is associated with high morbidity and mortality. Ann Trop Paediatr 2008; 28(4):287-292.

3. Singh AP, Jangid M, Ansari JS. Rare case of intussusception with malrotation and Meckel's diverticulum. JCR 2014; 4:338-340.

4. Bines JE, Liem NT, Justice FA. Risk factors for intussusception in infants in Vietnam and Australia: adenovirus implicated, but not rotavirus. J Pediatr. 2006;149:452-60.

5. Jang J, Lee YJ, Kim JS, Chung JY, Chang S, Lee K et al. Epidemiological Correlation between Fecal Adenovirus Subgroups and Pediatric Intussusception in Korea. Korean Med Sci 2017; 32: 1647-56.

6. Yih WK, Lieu TA, Kulldorff M. Intussusception risk after rotavirus vaccination in U.S. infants. N Engl J Med. 2014;370:503-12.

7. Esmaeili-Dooki MR, Moslemi L, Hadipoor A, Osia S, Fatemi SA. Pediatric Intussusception in Northern Iran: Comparison of Recurrent With Non-Recurrent Cases. Iran J Pediatr. 2016; 26(2): 3898

8. Henderson AA, Anupindi SA, Servaes S. Comparison of 2view abdominal radiographs with ultrasound in children with suspected intussusception. Pediatr Emerg Care 2013; 29(02):145-50.

9. Guo WL, Hu ZC, Tan YL, Sheng M, Wang J. Risk factors for recurrent intussusception in children: a retrospective cohort study. BMJ Open 2017;7:e018604.

10. Jiang J, Jiang B, Parashar U, Nguyen T, Bines J, Patel MM et al.Childhood Intussusception: A Literature Review. PLoS ONE 2017 July; 8(7): e68482. 